\title{
Condições de acesso à linha do Pronaf Agroecologia no Território da Cantuquiriguaçu/PR
}

\author{
Janete Stoffel \\ Universidade Federal da Fronteira Sul - Laranjeiras do Sul - Paraná - \\ Brasil \\ ORCID: https://orcid.org/0000-0003-0689-0414 \\ Anelise Graciele Rambo \\ Universidade Federal do Rio Grande do Sul- Tramandai - Rio Grande \\ do Sul - Brasil \\ ORCID: https://orcid.org/0000-0001-9974-9844 \\ Patrícia Luiza Eberhardt \\ Universidade Federal da Fronteira Sul - Laranjeiras do Sul - \\ Paraná - Brasil \\ ORCID: https://orcid.org/0000-0003-1267-3635
}

\begin{abstract}
Resumo
Com a instituição do Programa Nacional de Fortalecimento da Agricultura Familiar em 1995, os recursos financeiros voltados para a agricultura familiar passaram a ter um canal de acesso antes inexistente. Dentre os subprogramas do Pronaf está a linha voltada para a agroecologia, instituída a partir da safra 2003/2004, cujo acesso é baixo. Neste contexto o artigo aqui apresentado resulta de uma pesquisa que busca analisar limites e potencialidades no acesso dos agricultores familiares à linha do Pronaf Agroecologia no Território da Cidadania da Cantuquiriguaçu/PR. Foi utilizado instrumental descritivo exploratório, via um estudo de casos coletando dados junto a agricultores familiares e com agentes de instituições financeiras, buscando confrontar e comparar as respostas sobre a inexistência de acesso ao subprograma na região. Os resultados indicam que os agricultores familiares entrevistados, têm interesse em acessar os recursos, mas por desconhecimento, dificuldades quanto às exigências, receio quanto ao endividamento e taxas de juros, isto não acontece. No caso das instituições financeiras o que se observou é de que a linha não é atraente em termos financeiros para ser disponibilizada. Consequentemente não há um conhecimento apurado sobre como funciona e constata-se a necessidade de que a assistência técnica seja mais efetiva no sentido de instruir, orientar e auxiliar os agricultores familiares a apresentar projetos viáveis junto às instituições financeiras. Superar estes limites pode ser um meio de usufruir das potencialidades da produção agroecológica, tão importante e necessária para a sustentabilidade social, ambiental e econômica.
\end{abstract}

Palavras-chave: Recursos. Agricultura. Familiar. Agroecologia. Cantuquiriguaçu. 


\title{
Conditions for access to the Pronaf Agroecology line in the Territory of Cantuquiriguaçu/PR
}

\begin{abstract}
With the institution of the National Program to Strengthen Family Agriculture in 1995, financial resources for family agriculture had a previously non-existent access channel. Among the subprograms of Pronaf is the line focused on agroecology, instituted from the $2003 / 2004$ harvest, which has low access. In this context, the article presented here results from a research that seeks to analyze limits and potentialities in the access of family farmers to the Pronaf Agroecology line in the Cantuquiriguaçu / PR Citizenship Territory. Exploratory descriptive instruments were used, through a case study collecting data with family farmers and agents of financial institutions, seeking to compare and compare the answers about the lack of access to the subprogram in the region. The results indicate that the family farmers interviewed have an interest in accessing the resources, but due to lack of knowledge, difficulties regarding the requirements, fears about indebtedness and interest rates, this does not happen. In the case of financial institutions what has been observed is that the line is not attractive in financial terms to be made available. Consequently, there is no clear understanding of how it works and there is a need for technical assistance to be more effective in instructing, guiding and assisting family farmers to submit viable projects to financial institutions. Overcoming these limits can be a means of harnessing the potential of agroecological production, so important and necessary for social, environmental and economic sustainability.
\end{abstract}

Keywords: Resources. Agriculture. Familiar. Agroecology. Cantuquiriguaçu.

\section{Condiciones de acceso a la línea del Pronaf Agroecología en el Territorio de Cantuquiriguaçu/PR}

\section{Resumen}

Con la institución del Programa Nacional de Fortalecimiento de la Agricultura Familiar en 1995, los recursos financieros orientados a la agricultura familiar pasaron a tener un canal de acceso antes inexistente. Entre los subprogramas del Pronaf está la línea volcada hacia la agroecología, instituida a partir de la cosecha 2003/2004, cuyo acceso es bajo. En este contexto el artículo aquí presentado resulta de una investigación que busca analizar límites y potencialidades en el acceso de los agricultores familiares a la línea del Pronaf Agroecología en el Territorio de la Ciudadanía de Cantuquiriguaçu / PR. Se utilizó instrumental descriptivo exploratorio, a través de un estudio de casos recogiendo datos junto a agricultores familiares y con agentes de instituciones financieras, buscando confrontar y comparar las respuestas sobre la inexistencia de acceso al subprograma en la región. Los resultados indican que los agricultores familiares entrevistados, tienen interés en acceder a los recursos, pero por desconocimiento, dificultades en cuanto a las exigencias, temor en cuanto al endeudamiento y tasas de interés, esto no sucede. En el caso de las instituciones financieras lo que se ha observado es que la línea no es atractiva en términos financieros para ser puesta a disposición. En consecuencia, no hay un conocimiento apurado sobre cómo funciona y se constata la necesidad de que la asistencia técnica sea más efectiva en el sentido de instruir, orientar y auxiliar a los agricultores familiares a presentar proyectos viables ante las instituciones financieras. Superar estos límites puede ser un medio de usufructuar de las potencialidades de la producción agroecológica, tan importante y necesaria para la sostenibilidad social, ambiental y económica.

Palabras clave: Recursos. La agricultura. Familia. Agroecología. Cantuquiriguaçu. 


\section{Introdução}

Ao longo da história, na agricultura, houve o desenvolvimento de sistemas mais completos, diversos e adaptados ao local. No decorrer dos anos esses sistemas foram melhorados de modo a garantir a segurança alimentar, biodiversidade e recursos naturais. Essas melhorias proporcionavam a viabilidade da produção no longo prazo, pois resultava na diminuição do risco, maior diversificação e retorno para o agricultor, mesmo com baixa tecnologia e recursos limitados (ALTIERI, 2012).

Com a instituição do Programa Nacional de Fortalecimento da Agricultura Familiar (PRONAF), em 1996, passaram a ser ofertadas linhas que vão além do aspecto da modernização, mas também que demonstram preocupações com as questões sociais e ambientais defendidas por movimentos sociais. Conforme o MDA (2016, B) o Pronaf passou a incluir em suas linhas de crédito, a possibilidade de acesso a recursos para o desenvolvimento de uma agricultura sustentável e com dimensão ambiental, tais como o Pronaf Agroecologia, Pronaf Eco e Pronaf Floresta (MDA, 2018, A).

Com base na análise dos dados secundários, observa-se que nas linhas do Pronaf com foco na agricultura sustentável, o número de contratos e valores acessados é pequeno. A título de ilustração, no recorte do período de 2013 a 20150 volume de recursos disponibilizados para as linhas Pronaf Agroecologia, Pronaf Eco e Pronaf Floresta foi orçado em R\$ 2.5 bilhões, mas somente $2,5 \%$ desse montante foram executados. Este percentual correspondeu a 1.973 (Um mil novecentos e setenta e três) contratos efetuados em todos os municípios do Brasil (MDA, 2016, C).

Diante do baixo acesso, fica evidente a existência de problemas referentes a essas linhas. Em uma análise inicial parece haver desconhecimento por parte dos agricultores familiares, desvalorização dessas linhas de crédito por parte das instituições financeiras, bem como por parte dos técnicos que elaboram os projetos, dentre outras barreiras que impedem os agricultores familiares de acessar estes recursos. Vale ressaltar, com base em MDA (2016,C), que no caso do Pronaf Agroecologia foram apresentadas medidas que permitiram a utilização de bônus por adimplência, prazos maiores, disponibilidade de carências, juros mais baixos, ATER embutida.

Segundo MDA (2013) a linha do Pronaf Agroecologia beneficia agricultores que produzem alimentos orgânicos e agroecológicos que podem ser desde assentados, agricultores de propriedades familiares, e outros grupos como povos ou comunidades. Considerando que o acesso é baixo a estes recursos e com base nessas evidências iniciais, este artigo se propõe a analisar quais os limites e potencialidades para o acesso de agricultores familiares à linha do Pronaf Agroecologia, no Território da Cidadania Cantuquiriguaçu? Para obter estas respostas, além de um levantamento de dados secundários no Banco Central foram efetuadas entrevistas com agricultores e instituições financeiras na região mencionada.

Para dar conta desta abordagem, a estrutura do presente artigo conta, além desta introdução, com uma segunda seção que aborda aspectos sobre a produção agroecológica na agricultura familiar, bem como apresenta informações referentes à linha do Pronaf Agroecologia. Na sequência constam os procedimentos 
metodológicos utilizados na pesquisa, com uma descrição da região na qual o estudo foi realizado e, por fim, os resultados obtidos bem como as considerações finais e referências bibliográficas utilizadas.

\section{A produção agroecológica na agricultura familiar e o acesso à linha do Pronaf Agroecologia}

$\mathrm{Na}$ análise do período histórico a partir de meados do Século XX, agricultura brasileira foi sendo moldada, predominantemente, pela modernização conservadora. Esse processo se desenrolou com a promessa de aumentar a produtividade e resolver as questões que envolvem a fome. Ainda que tenha contribuído com a produção de alguns cultivos, mostrou não ser sustentável, não resolveu o problema da fome e ocasionou perdas irreparáveis à biodiversidade, ao solo, à saúde, ao conhecimento tradicional dos agricultores, causando dependência em relação aos recursos externos (ABRAMOVAY, 1998). Além disso, a modernização agrícola favoreceu os agricultores patronais ${ }^{1}$ em detrimento dos agricultores familiares, os quais para acompanhar as tecnologias e os pacotes disseminados na Revolução Verde, ficaram endividados (ALTIERI, 2004). Algumas políticas públicas também contribuíram para a condução dos agricultores familiares à problemática supracitada, especialmente aquelas vinculadas ao crédito rural vinculado à modernização conservadora.

A agricultura familiar caracteriza-se pela diversificação da produção, com condições mais favoráveis para a distribuição de renda equitativa, e em condições de desenvolver predominantemente um modelo com práticas sustentáveis em comparação com a agricultura patronal (VEIGA, 1996). Na percepção de autores como Altieri (2012), da agricultura familiar espera-se uma prática agrícola mais voltada para a sustentabilidade, com preocupações sociais, ambientais, além das econômicas. Entretanto, ainda é grande a quantidade de agricultores familiares que produzem de modo convencional ${ }^{2}$, os quais adotam o "pacote" produtivo semelhante aos agricultores patronais.

Estas práticas são consequências de demandas impostas sobre as áreas agrícolas, pela economia globalizada, induzindo assim muitos agricultores familiares a utilizar o modelo convencional. E as culturas desenvolvidas anualmente, neste

\footnotetext{
${ }^{1}$ Categoria que busca concentrar a sua riqueza através da maximização dos lucros e melhoramento da produção, utilizando-se da especialização produtiva, resultando em exclusão social e contribuindo para a elevação do grau de desigualdade na distribuição de renda (VEIGA, 1996).

2 Produção caracterizada pela dependência crescente de agroquímicos (inseticidas, herbicidas, fungicidas, fertilizantes); contaminação de alimentos, águas, solos e pessoas por pesticidas e produtos derivados do uso de fertilizantes sintéticos; desenvolvimento de resistência dos praguicidas para certas pragas e patógenos; perda da capacidade produtiva dos solos, devido à erosão, degradação, salinização e desertificação dos mesmos. Perda de nutrientes dos solos devido à falta de reposição, junto com lixiviação e baixa eficiência dos usos de fertilizantes; contaminação do corpo de água (sedimentos). Perda da biodiversidade: efeito de agroquímicos e simplificação dos habitats; perda da variabilidade genética dos principais cultivos (erosão génica); o desaparecimento de algumas técnicas de cultivos própria de agricultores/as tradicionais por tecnologias "modernas" supostamente de aplicação universal (erosão cultural); contribuição da calefação global no planeta e diminuição na camada de ozônio; não tem solucionado o problema de pobreza rural (SARANDÓN e FLORES, 2014).
} 
modelo de produção, são principalmente monoculturas com alto nível de dependência de insumos provenientes do meio externo, tais como os fertilizantes e agrotóxicos. Esses cultivos avançam sobre as áreas de florestas e vegetação natural, além de homogeneizar a produção, provocando fragilidade nos cultivos e mudanças climáticas.

Neste cenário a agricultura familiar desenvolvendo a produção agroecológica ${ }^{3}$ exerce papel de destaque, tal como apontam Heberlê et al (2017), para quem essa forma de produção propicia a segurança alimentar, nutricional, recuperação de alimentos tradicionais e alimentação balanceada. Contribui ainda para a agro biodiversidade, para o uso sustentável dos recursos provenientes da natureza, além de impulsionar a economia local, principalmente quando está articulada com políticas que buscam a autonomia do agricultor, geração de trabalho e contribuem para resolver os problemas de mudanças climáticas e consumo.

$O$ reconhecimento da agricultura familiar enquanto categoria, resultando na implantação de intervenções estatais é recente. Desponta na década de 90, período este em que a categoria ganha expressividade e um delineamento. Em 1995 foi criado o Programa Nacional de Fortalecimento da Agricultura Familiar - Pronaf, com a finalidade de estimular o desenvolvimento sustentável do segmento rural composto pelos agricultores familiares, através do acesso ao crédito (BRASIL, 2018), a partir do qual houve uma caracterização formal deste grupo.

No Pronaf, o agricultor familiar beneficiário é compreendido como aquele que desenvolve atividades no meio rural e que detém: a) área de até 4 módulos fiscais; b) que utiliza mão de obra predominantemente familiar nas atividades produtivas exercidas no estabelecimento; c) cuja renda seja oriunda predominantemente do estabelecimento; e d) onde o proprietário em conjunto com a família dirija o estabelecimento (LEI 11326/06, 2010; BRASIL, 2019).

O Pronaf Agroecologia é oficializado enquanto linha do Pronaf na safra 2005/2006 (BIANCHINI, 2015). Neste subprograma os recursos são direcionados para investimentos na produção agroecológica ou orgânica, seja na instituição ou na manutenção destes sistemas e suas respectivas estruturas de produção, ou ainda para produtores que estejam efetuando a transição para a agroecologia ou para a produção orgânica, desde que atendidas as regras estabelecidas pelo MAPA (Ministério da Agricultura Pecuária e Abastecimento) e pelo MDA (Ministério do

\footnotetext{
${ }^{3}$ Neste modelo de produção há uma produção eficiente e rentável a longo prazo (considerando o custo ecológico) que promove a conservação do solo, água, energia e recursos biológicos (como a biodiversidade); uma diminuição no risco devido a frustação ambiental (bióticas e abióticas) o de mercado. Lograr uma maior estabilidade e resistência no tempo; Uso e degradação dos recursos naturais renováveis em ritmo menor ou igual a sua taxa de reposição; Um uso de exploração dos recursos não renováveis a um ritmo menor ou igual a da taxa de desenvolvimento de tecnologia alternativas; emissão de resíduos similar ou menos na capacidade de assimilação do ambiente; uma menor dependência do uso de insumos externos (combustíveis fósseis, praguicidas, fertilizantes sintéticos, etc.); Um uso mais eficiente da energia (principalmente fóssil); Um maior aproveitamento de processos naturais na produção agrícola (reciclagem de matéria orgânica e nutrientes, fixação de nitrógeno, alelopatia e relação predador-presa); Uma eliminação ou diminuição dos danos no ambiente, a outras espécies, e/ou a saúde de agricultores e consumidores; Um ajuste do sistema de cultivo à produtividade potencial e não limitantes físicas, econômicas e socioculturais do agroecossistemas; um desenvolvimento de tecnologia que seja cultural e socialmente aceitáveis (SARANDÓN e FLORES, 2014).
} 
Desenvolvimento Agrário) (MDA, 2018 D). Assim como as demais linhas disponíveis, o Pronaf Agroecologia é destinado aos agricultores familiares que apresentem Declaração de Aptidão ao Pronaf (DAP), que especificamente tenham produção orgânica ou agroecológica ou estejam em transição para à agroecologia.

Com a finalidade de apresentar informações sobre o acesso ao subprograma do Pronaf Agroecologia, na Tabela 1 constam informações detalhadas sobre 0 número de contratos e valores acessados. Estes dados estão disponíveis por Unidade da Federação (UF) e separados pelas atividades agrícola e pecuária para as quais os recursos foram acessados.

Tabela 1 - Número e valores dos contratos efetuados pela linha do Pronaf Agroecologia por Unidade da Federação, considerando atividade agrícola e pecuária entre janeiro de 2013 e janeiro de 2018

\begin{tabular}{|c|c|c|c|c|c|c|c|c|}
\hline $\begin{array}{l}\text { Esta- } \\
\text { do }\end{array}$ & $\begin{array}{l}\text { Con- } \\
\text { tratos }\end{array}$ & Agrícola & $\begin{array}{c}\% \\
\text { sobre } \\
\text { total } \\
\text { UF }\end{array}$ & $\begin{array}{c}\text { Con- } \\
\text { tratos }\end{array}$ & Pecuária & $\begin{array}{c}\text { \% sobre } \\
\text { total } \\
\text { UF }\end{array}$ & $\begin{array}{c}\text { Con- } \\
\text { tratos }\end{array}$ & Valores \\
\hline RS & 118 & $5.288 .531,33$ & $94 \%$ & 9 & $308.538,00$ & $6 \%$ & 127 & $5 \cdot 597.069,33$ \\
\hline SC & 60 & $2.313 \cdot 539,88$ & $95 \%$ & 3 & $114.615,82$ & $5 \%$ & 63 & $2.428 .155,70$ \\
\hline PR & 17 & $776.871,95$ & $100 \%$ & & & $0 \%$ & 17 & $776.871,95$ \\
\hline PB & 30 & $204.068,18$ & $8 \%$ & 437 & $2.439 \cdot 359,31$ & $92 \%$ & 467 & $2.643 \cdot 427,49$ \\
\hline$A L$ & 26 & $394.773,51$ & $58 \%$ & 35 & 289.691,96 & $42 \%$ & 61 & $684.465,47$ \\
\hline PE & 8 & $314.230,43$ & $100 \%$ & & & $0 \%$ & 8 & $314.230,43$ \\
\hline BA & 6 & $167 \cdot 971,62$ & $100 \%$ & & & $0 \%$ & 6 & $167.971,62$ \\
\hline CE & 7 & $82.164,55$ & $63 \%$ & 3 & $49.192,56$ & $37 \%$ & 10 & $131.357,11$ \\
\hline $\mathrm{RN}$ & 12 & $38.218,04$ & $36 \%$ & 10 & $68.540,94$ & $64 \%$ & 22 & $106.758,98$ \\
\hline MA & 1 & $99.960,00$ & $100 \%$ & & & $0 \%$ & 1 & $99.960,00$ \\
\hline ES & 53 & $2.661 .291,74$ & $99 \%$ & 2 & $14.817,20$ & $1 \%$ & 55 & $2.676 .108,94$ \\
\hline MG & 11 & $290.719,69$ & $48 \%$ & 9 & $314.770,94$ & $52 \%$ & 20 & $605.490,63$ \\
\hline SP & 4 & $211.450,73$ & $100 \%$ & & & $0 \%$ & 4 & $211.450,73$ \\
\hline RJ & 1 & $20.579,49$ & $100 \%$ & & & $0 \%$ & 1 & $20.579,49$ \\
\hline PA & 1 & $27.858,24$ & $100 \%$ & & & $0 \%$ & 1 & $27.858,24$ \\
\hline $\mathrm{AM}$ & 1 & $7 \cdot 334,82$ & $100 \%$ & & & $0 \%$ & 1 & $7 \cdot 334,82$ \\
\hline Total & 356 & 12.899 .564 & $78 \%$ & 508 & 3.599 .527 & $22 \%$ & 864 & 16.499 .091 \\
\hline
\end{tabular}

Fonte: Elaborada a partir dos dados do Bacen, 2018

Obs.: São consideradas pessoas físicas que acessaram aos recursos, sendo estas beneficiárias vinculadas ao Pronaf e os recursos destinados ao investimento.

Destaque-se na Tabela 1 que no período de janeiro de 2013 a janeiro de 2018, foram efetuados no Brasil 864 contratos do Pronaf Agroecologia. Deste total, 356 são de atividades agrícolas e 508 de pecuária. Em relação aos montantes financeiros o total de contratos neste período correspondeu a $\mathrm{R} \$ 16.499 .091,00$, sendo que $78 \%$ foi destinado às atividades agrícolas e $22 \%$ às atividades pecuárias. A título de comparação, neste mesmo período o valor total de recursos acessados pelo Pronaf foi de $\mathrm{R} \$$ 110.577.553.335,31, o que revela a baixa participação do subprograma Pronaf Agroecologia (0,015\% sobre o total) no acesso ao montante de recursos destinados à totalidade dos subprogramas do Pronaf (BACEN, 2018). 
No período apresentado na Tabela 1 o subprograma em questão foi acessado em 16 (dezesseis) das Unidades da Federação(UF) do país, sendo que os três com maior número de contratos foram, respectivamente, Paraíba com 467, Rio Grande do Sul com 127 e Santa Catarina com 63 contratos. Entretanto, quando a observação recai sobre o montante acessado a ordem dos três primeiros se altera, sendo o Rio Grande do Sul aquele em que os agricultores familiares acessaram o maior volume, seguido pelo Espírito Santo e então a Paraíba. Estes resultados indicam que no caso da Paraíba as médias de volumes por contratos são menores do que as do Rio Grande do Sul, por exemplo.

Para complementar informações, na Tabela 2, além do número de contratos e valor acessado nas UF as informações estão sistematizadas por Região e ainda apresentados os valores médios dos contratos efetuados.

Tabela 2 - Contratos e valores, em termos nominais, do Pronaf Agroecologia no

Brasil, Grandes Regiões e Estados, entre janeiro de 2013 e janeiro de 2018

\begin{tabular}{|c|c|c|c|c|c|}
\hline \multirow[t]{2}{*}{ Região } & \multirow[t]{2}{*}{ UF } & \multirow[t]{2}{*}{$\begin{array}{l}\text { número de } \\
\text { municípios }\end{array}$} & \multicolumn{2}{|c|}{$\begin{array}{l}\text { em relação aos contratos } \\
\text { efetuados }\end{array}$} & \multirow{2}{*}{$\begin{array}{l}\text { valor médio } \\
\text { dos contratos }\end{array}$} \\
\hline & & & $\begin{array}{r}\text { número de } \\
\text { contratos }\end{array}$ & valor contratado & \\
\hline \multirow{7}{*}{ SUL } & RS & 26 & 127 & $5.597 .069,33$ & $44.071,41$ \\
\hline & SC & 27 & 63 & $2.428 .155,70$ & $38.542,15$ \\
\hline & PR & 6 & 17 & $776.871,95$ & $45.698,35$ \\
\hline & total & 59 & 207 & $8.802 .096,98$ & $42.522,21$ \\
\hline & PB & 25 & 467 & $2.643 .427,49$ & $5.660,44$ \\
\hline & $A L$ & 4 & 61 & $684.465,47$ & $11.220,75$ \\
\hline & PE & 2 & 8 & $314.230,43$ & $39.278,80$ \\
\hline \multirow[t]{6}{*}{ NORDESTE } & BA & 3 & 6 & $167.971,62$ & $27.995,27$ \\
\hline & CE & 4 & 10 & $131.357,11$ & $13.135,71$ \\
\hline & $\mathrm{RN}$ & 2 & 22 & $106.758,98$ & $4.852,68$ \\
\hline & MA & 1 & 1 & $99.960,00$ & $99 \cdot 960,00$ \\
\hline & Total & 41 & 575 & 4.148.171,10 & $7.214,21$ \\
\hline & ES & 6 & 55 & $2.676 .108,94$ & $48.656,53$ \\
\hline \multirow[t]{4}{*}{ SUDESTE } & MG & 9 & 20 & $605.490,63$ & $30.274,53$ \\
\hline & $\mathrm{SP}$ & 3 & 4 & $211.450,73$ & $52.862,68$ \\
\hline & RJ & 1 & 1 & $20.579,49$ & $20.579,49$ \\
\hline & total & 19 & 80 & $3.513 .629,79$ & $43 \cdot 920,37$ \\
\hline \multirow[t]{3}{*}{ NORTE } & $\mathrm{PA}$ & 1 & 1 & $27.858,24$ & $27.858,24$ \\
\hline & AM & 1 & 1 & $7 \cdot 334,82$ & $7 \cdot 334,82$ \\
\hline & total & 2 & 2 & $35.193,06$ & $7 \cdot 596,53$ \\
\hline Total Brasil & & 121 & 864 & $16.499 .090,93$ & $19.096,17$ \\
\hline
\end{tabular}

Fonte: Adaptado pela autora a partir dos dados do Bacen, 2018.

A primeira observação a ser realizada, a partir da Tabela 2, é de que no período analisado (janeiro de 2013 a janeiro de 2018) não houve acesso ao subprograma do Pronaf Agroecologia na Região Centro-Oeste. Dentre as outras quatro regiões, é possível constatar que o maior volume foi acessado pelos Estados da Região Sul, enquanto o maior número de contratos foi firmado na Região Nordeste e o maior número de municípios em que a linha foi acessada foi na Região 
Sul. Já o maior valor médio por contrato aparece na Região Sudeste, enquanto o menor valor médio está na Região Nordeste.

Uma UF que merece destaque é a Paraíba na qual durante o período considerado foram efetuados 467 contratos, correspondente a $81 \%$ do total de contratos da região Nordeste e a $54 \%$ da totalidade de contratos efetuados no período entre todas as Unidades da Federação. Conforme informações obtidas no site do Governo da Paraíba (2018), nesse estado são desenvolvidas ações para incentivar a produção orgânica. Essas envolvem uma gestão unificada entre a Empresa Estadual de Pesquisa Agropecuária da Paraíba (Emepa), Instituto de Terras e Planejamento Agrícola do Estado da Paraíba (Interpa) e Emater, ligados a Secretaria de Estado do Desenvolvimento da Agropecuária e Pesca (Sedap).

Ainda conforme o Governo da Paraíba (2018), essa gestão proporcionou a formação complementar dos extensionistas, a inserção dos agricultores no PAA (Programa de Aquisição de Alimentos) e PNAE (Programa Nacional de Alimentação Escolar), o fornecimento de cursos de capacitação pela Emater com duração de 3 anos para os agricultores. Ressalta-se que ainda há outras ações do governo estadual da Paraíba para fortalecer a agricultura familiar, como a realização de Encontros da Juventude Rural, de modo a proporcionar o conhecimento de experiências e propiciar discussões sobre as Políticas Públicas. Além disso há o Projeto Eco produtivo, que contempla assentamentos e comunidades quilombolas através da promoção da sustentabilidade na sua produção e melhoria das condições socioeconômicas dos agricultores familiares.

Observando o Estado do Paraná, no qual está situada a região em que foi realizado este estudo, no período analisado foram efetuados 17 contratos em 6 municípios (do total de 399 municípios paranaenses), sendo eles: Tijucas do Sul, Araucária, Cascavel, Palmeira, Guaíra, Jataizinho. O valor total acessado correspondeu a $\mathrm{R} \$ 776.871,95$ no período.

$\mathrm{Na}$ Tabela 3 consta o detalhamento quanto ao número de contratos e valores acessados em cada um dos seis municípios Paranaenses, que tiveram acesso ao subprograma Pronaf Agroecologia, no período de janeiro de 2013 a janeiro de 2018. Em Tijucas do Sul foram efetuados $59 \%$ dos contratos do Estado e $52 \%$ do montante de valores acessados.

Tabela $3^{4}$ - Número de contratos assinados e valores contratados no Pronaf Agroecologia, nos municípios do Paraná entre janeiro de 2013 e janeiro de 2018

\begin{tabular}{lrrr}
\hline \multicolumn{1}{c}{ Município } & \multicolumn{2}{c}{$\begin{array}{c}\text { Em relação aos contratos efetuados } \\
\text { Número de contratos }\end{array}$} & $\begin{array}{c}\text { Valor médio por } \\
\text { contrato }\end{array}$ \\
\hline TIJUCAS DO SUL & 10 & $405.851,89$ & $40.585,19$ \\
ARAUCÁRIA & 1 & $117.900,00$ & $117.900,00$ \\
CASCAVEL & 1 & $114.418,00$ & $114.418,00$ \\
PALMEIRA & 2 & $60.972,02$ & $30.486,01$ \\
GUAÍRA & 1 & $53.188,65$ & $53.188,65$ \\
JATAIZINHO & 2 & $24.541,39$ & $12.270,70$ \\
Total & 17 & $\mathbf{7 7 6 . 8 7 1 , 9 5}$ & $\mathbf{4 5 . 6 9 8 , 3 5}$ \\
\hline
\end{tabular}

Fonte: Adaptado pela autora dos dados do Bacen, 2018.

\footnotetext{
${ }^{4}$ As informações são referentes ao Programa Pronaf, subprograma Agroecologia, com contratos e recursos destinados para investimentos na atividade agrícola.
} 
Dentre os municípios citados na Tabela 3 o mais próximo da região em estudo é Cascavel, no qual foi efetuado um único contrato no período considerado. Assim, no caso do Território da Cidadania da Cantuquiriguaçu, o intuito do estudo é buscar compreender os motivos pelos quais os agricultores familiares da região não acessam a essa linha de crédito. Na continuidade deste texto está apresentada a metodologia utilizada para efetuar o levantamento de informações primárias na busca de respostas ao problema de pesquisa estabelecido.

\section{Metodologia de Pesquisa}

A pesquisa aqui relatada utilizou-se de características exploratóriodescritivas. No aspecto exploratório consiste em analisar condições de acesso de agricultores familiares do Território da Cidadania Cantuquiriguaçu à linha do Pronaf Agroecologia. Quanto à descrição foram apresentadas informações sobre agricultores familiares, se estes acessam ao subprograma, e como a resposta negativa já é conhecida, quais as dificuldades existentes. A pesquisa tem abordagem qualitativa, que para Oliveira (2007, p.37) consiste em uma "[...] reflexão e análise da realidade através da utilização de métodos e técnicas para compreensão detalhada do objeto de estudo [...]". Assim, para a obtenção dos dados foram utilizados documentos/referências teóricas, questionários, entrevistas, análises de dados, considerados também recursos de pesquisa descritiva, segundo a autora supracitada.

No referencial teórico foram utilizadas fontes que abordam as temáticas da agroecologia, da agricultura familiar e do Pronaf. Em relação ao subprograma Pronaf Agroecologia foram acessadas informações estatísticas com base em dados secundários. A principal fonte de dados é o site do Banco Central, na seção sobre estabilidade financeira/supervisão/crédito rural/matriz de dados do crédito rural, local em que estão disponíveis informações sobre o acesso a esta linha de crédito.

Quanto ao procedimento de coleta de dados primários, a pesquisa classificase como um estudo de casos. Segundo Chizzotti (2006) esse estudo busca explorar casos que estão delimitados e contextualizados em um tempo e local para fazer uma busca de informações referente a um caso específico. Esse caso pode ser apenas um, dois ou mais, ou pode ser uma coleção de casos referentes a um aspecto que está acontecendo nesses casos individuais. Para Yin (1994) os casos múltiplos são como um conjunto de experiências múltiplas e através dos resultados empíricos desses casos é possível a elaboração prévia de uma teoria para servir mais à frente como um suporte para o estudo.

No estudo de casos efetuado nesta pesquisa, foram entrevistados agricultores familiares e agentes de instituições financeiras. Quanto ao primeiro grupo o objetivo era conhecer os motivos pelos quais não acessam ao subprograma Pronaf Agroecologia e no segundo grupo buscou-se obter informações que pudessem complementar (ou confrontar) as respostas dos agricultores familiares.

A estratégia utilizada para localizar agricultores familiares que desenvolvem produção orgânica ou agroecológica foi participar de feiras que tivessem vínculo com este tipo de produção. Assim, no ano de 2018 foram visitadas três feiras realizadas em municípios da região delimitada. As feiras visitadas foram: a) $2^{\circ}$ Feira 
Agropecuária e Encontro de Criadores de Caprinos e Ovinos do Território da Cantuquiriguaçu (Expovir) no município de Virmond/PR, (visitada no dia 18 de maio de 2018); b) $6^{\circ}$ Feira Regional de Economia Solidária e Agroecologia (FESA) em Laranjeiras do Sul/PR (entrevistas foram realizadas no dia 19 de maio de 2018); c) $17^{\circ}$ Festa do Agricultor e Motorista no município de Cantagalo/PR (visita realizada em 28 de julho de 2018).

Nas feiras o critério de escolha dos entrevistados levou em conta a necessidade de ser agricultor familiar e desenvolver produção orgânica ou agroecológica (certificado ou em transição). Em termos de instrumento foi utilizado um roteiro semi-estruturado para a realização das entrevistas e obtenção das informações. Nestas feiras foram pesquisados 12 (doze) agricultores familiares, cujas informações estão disponíveis na seção 5, sendo apresentadas coletivamente, preservando a identidade dos entrevistados. A partir das respostas obtidas junto aos agricultores familiares e constatando que as informações se repetiam, as pesquisadoras destinaram esforços para buscar informações complementares em instituições financeiras que disponibilizam o subprograma Pronaf Agroecologia. De um total de cinco (5) instituições procuradas, quatro (4) participaram da pesquisa.

Nas instituições financeiras as entrevistas foram realizadas pessoalmente com a utilização de um roteiro semi-estruturado. $\mathrm{Na}$ apresentação dos resultados as quatro instituições foram denominadas pelas letras A, B, C e D e as informações obtidas nas entrevistas são apresentadas na seção 5 deste artigo. O objetivo do trabalho foi compreender os limites e potencialidades do acesso à linha do Pronaf Agroecologia no Território da Cidadania da Cantuquiriguaçu, sem expor pessoas ou instituições.

Os resultados obtidos a partir das entrevistas estão apresentados na seção 5, mas antes destas informações julgamos importante apresentar ao leitor as características do espaço regional no qual a pesquisa foi realizada, facilitando a localização para todos.

\section{O Território da Cidadania da Cantuquiriguaçu}

O Território da Cidadania Cantuquiriguaçu ${ }^{5}$, localizado no Estado do Paraná, foi parte integrante do Programa Territórios da Cidadania do governo federal, criado em 2008. A região é constituída por vinte municípios, sendo eles: Porto Barreiro, Campo Bonito, Candói, Cantagalo, Catanduvas, Espigão Alto do Iguaçu, Foz do Jordão, Goioxim, Guaraniaçu, Ibema, Laranjeiras do Sul, Marquinho, Nova Laranjeiras, Pinhão, Quedas do Iguaçu, Reserva do Iguaçu, Rio Bonito do Iguaçu, Três Barras do Paraná, Virmond e Diamante do Sul. Na Figura 1 é apresentada a localização da região utilizada como referência na presente pesquisa.

\footnotetext{
${ }^{5}$ O nome Cantuquiriguaçu é uma referência aos rios que delimitam o Território: ao Norte, o Rio Piquiri; ao Sul, o Rio Iguaçu; e ao Oeste, o Rio Cantu.
} 
Figura 1- Mapa do território da Cidadania Cantuquiriguaçu

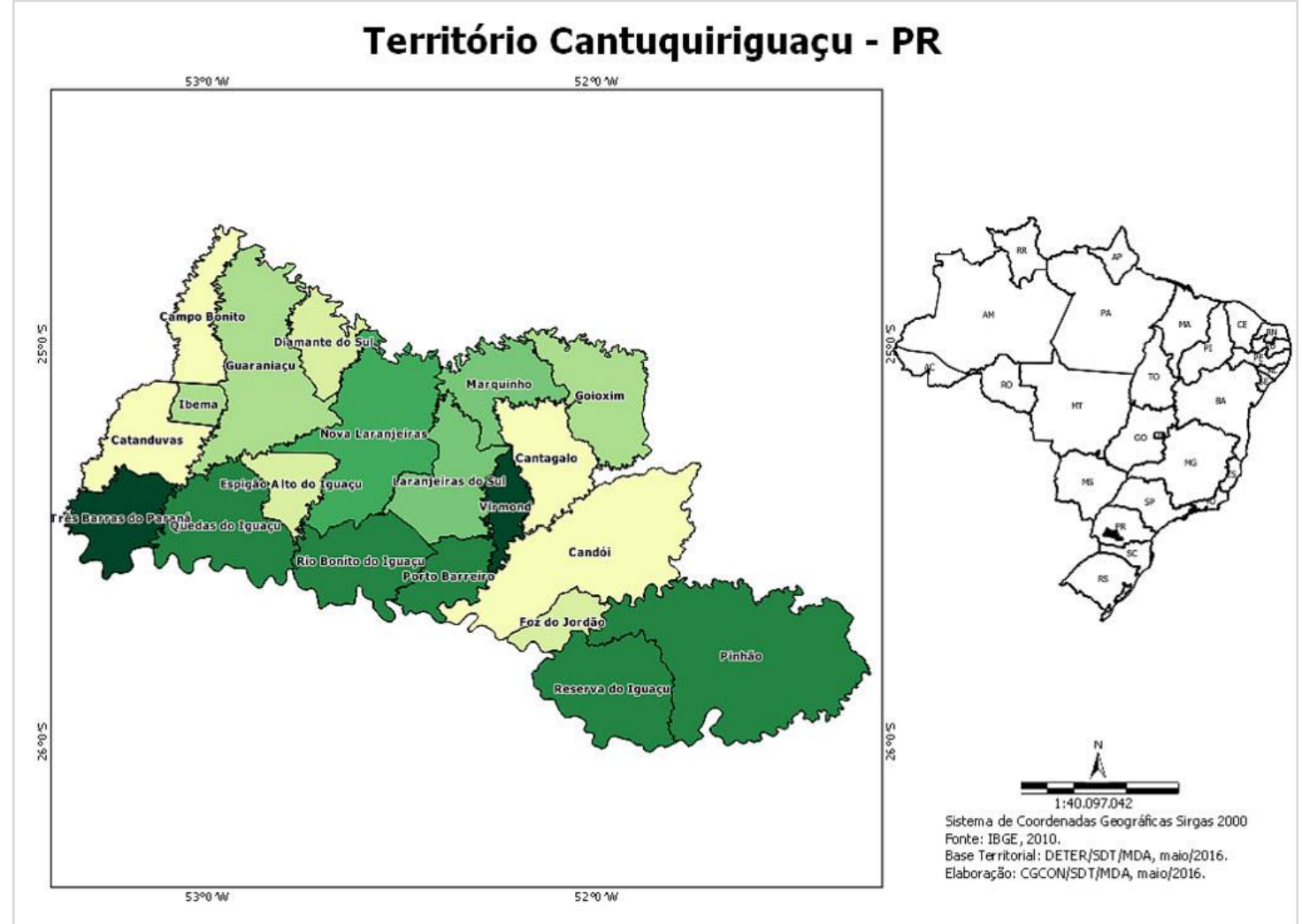

Fonte: Portal dos NEDET, 2016

A região do território possui uma terra indígena regularizada, denominada Rio das Cobras localizada nos municípios de Nova Laranjeiras e Espigão Alto do Iguaçu, contando com uma superfície de 18.681,9806 hectares. Outra terra indígena declarada em Laranjeiras do Sul, denominada Boa Vista-PR, com uma superfície de 7.336,3308 hectares (FUNAI, 2016; ITCG, 2008). Há ainda na região, segundo as fontes supracitadas, aproximadamente 4,3 mil famílias assentadas e 21.184 mil estabelecimentos da agricultura familiar, além de uma comunidade quilombola localizada no município de Candói.

A população total da região é de 232.519 habitantes, dos quais 125.060 (54\%) moram em áreas urbanas e 107.459 (46\%) em áreas rurais, havendo 60.433 pessoas ocupadas na agricultura familiar (IBGE, 2016; PORTAL DOS NEDETS, 2016). Assim, predominam características rurais na região, sendo que dentre os municípios que a compõem Laranjeiras do Sul é aquele com a maior população, cerca de 32 mil habitantes enquanto o menor é Diamante do Sul com 3.510 habitantes em 2010, conforme as fontes supracitadas.

Os dados secundários oriundos do Banco Central indicam que não houve acesso na região do território ao subprograma Pronaf Agroecologia, por isso este trabalho buscou fazer uma investigação de motivos que podem explicar o porquê de não haver acesso a esse crédito na região. Na próxima seção constam os dados que foram identificados a partir da pesquisa realizada. 


\section{Condições de acesso ao Pronaf agroecologia na região do Território da Cidadania da Cantuquiriguaçu/PR: na perspectiva de agricultores familiares e de agentes financeiros}

O estudo, aqui apresentado, tem como objetivo analisar as condições de acesso ao Programa Nacional de Fortalecimento da Agricultura Familiar, no Território da Cidadania Cantuquiriguaçu, no que tange ao estímulo para a produção agroecológica. Nesta seção o foco está na análise dos limites e potencialidades do Programa Nacional de Fortalecimento da Agricultura Familiar, no Território da Cidadania Cantuquiriguaçu, destacando o acesso para a Agroecologia, no subprograma com esta denominação.

No contexto da realidade do Território da Cidadania Cantuquiriguaçu, esse estudo procurou compreender as linhas de crédito voltadas para a dimensão social e ambiental que têm pouco acesso no país e nenhum acesso nesta região. Quanto ao levantamento dos dados primários, utilizados nesta pesquisa, inicialmente foram obtidas informações com agricultores familiares, visando entender os motivos de não haver acesso ao subprograma do Pronaf voltado para a agroecologia. A estratégia utilizada para obter essas informações foi a participação em feiras e eventos promovidos na região, tendo sido visitados os seguintes eventos: a) $2^{\text {a }}$ Feira Agropecuária e Encontro de Criadores de Caprinos e Ovinos do Território da Cantuquiriguaçu (EXPOVIR) na cidade de Virmond; b) $6^{\circ}$ Feira Regional de Economia Solidária e Agroecologia (FESA) no município de Laranjeiras do Sul; e c) $17^{\mathrm{a}}$ Festa do agricultor e do motorista em Cantagalo.

A $2^{\circ}$ Expovir aconteceu entre os dias 18 e 19 de maio de 2018, no Município de Virmond/PR, tendo como ênfase as atividades Agropecuárias com destaque para as produções pecuárias de caprino e ovinos. Devido a esta ênfase a feira estava organizada em três grandes grupos: Turismo e gestão pública; Gado leiteiro; Caprinos e Ovinos. Apesar de não haver um foco específico em agroecologia, havia expositores de produtos orgânicos na seção de caprinos e ovinos. Neste local foi entrevistada uma família, a qual ao ser questionada sobre o Pronaf Agroecologia, afirmou desconhecer o subprograma. Ao serem explicadas as características da linha demonstrou interesse em acessar. No diálogo ficou evidenciada a necessidade desse recurso para investir em sua Agroindústria com produção orgânica.

$\mathrm{Na} 6^{\circ}$ FESA que aconteceu no dia 19 de maio de 2018, na praça central do município de Laranjeiras do Sul/PR, foram entrevistados 10 grupos de agricultores familiares. Esta feira destaca-se pela comercialização de produtos agroecológicos, coloniais e artesanatos dos agricultores familiares da região. A feira oferta ainda oficinas temáticas, atividades culturais e a possibilidade de troca de sementes e mudas entre todos que desejarem.

Já na Festa do agricultor e do motorista, que ocorreu nos dias 28 e 29 de julho de 2018 no Município de Cantagalo/PR, o foco do evento era o encontro entre produtores de leite. Neste local foi entrevistado um agricultor com produção orgânica.

Assim, nos três eventos foram realizadas 12 entrevistas com agricultores familiares que tem vínculo com a produção agroecológica. Em relação à origem dos entrevistados, cabe destacar que são provenientes dos municípios de Guaraniaçu, 
Laranjeiras do Sul, Nova Laranjeiras, Pinhão, Rio Bonito, Cantagalo, Laranjal ${ }^{6}$ e de Palmital. Quanto à idade a amplitude foi de 22 aos 63 anos para os agricultores entrevistados, sendo que a metade dos pesquisados tem até 41 anos. Quanto ao gênero, 75\% dos entrevistados são do sexo feminino. O tamanho dos estabelecimentos nos quais trabalham e produzem varia de 3,63 ha ${ }^{7}$ a 60 ha.

Em relação à forma de aquisição da terra na qual trabalham, os entrevistados são agricultores familiares com títulos de propriedades, assentados, acampados e moradores de terras indígenas. Essa diversidade vem ao encontro das características que o território tem e que já foram elencadas na seção 4 deste texto.

Sobre a produção desenvolvida nas propriedades, dos agricultores entrevistados, constatou-se que produzem folhosas (alface, almeirão, repolho e rúcula), tuberosas ou raízes (cenoura, beterraba, batata doce, mandioca, batata), floríferas (brócolis, couve-flor), frutas (tomate, banana, laranja, pokãn, amora, laranja, abacate, mamão), leguminosas (feijão e amendoim), condimentos aromáticos (cebolinha e salsinha), grãos (arroz, milho e pipoca) e bovinocultura (leite e derivados como queijos, doces, requeijão e manteiga).

Quanto à produção orgânica, observou-se que na maioria das propriedades esta ocupa parte da unidade produtiva, havendo o consórcio com atividades não orgânicas. Do total de entrevistados foi possível observar que $42 \%$ afirmou que possui o selo de produção orgânica.

A comercialização da produção é feita principalmente nos comércios locais. Em alguns casos os produtos chegam até municípios maiores como Guarapuava, Londrina, Maringá e Curitiba. Nos canais de comercialização utilizados observou-se que predomina a utilização da feira livre, seguida pela comercialização via PNAE e PAA. Também foram mencionadas as vendas efetuadas de porta em porta e por fim em supermercados. Sendo esta a ordem com a qual os canais de comercialização são utilizados. É importante destacar que dentre os entrevistados, cerca de $85 \%$ é de agricultores familiares que se organiza de modo coletivo, com destaque para cooperativas, associações e redes ${ }^{8}$.

Quando questionados se já acessaram qualquer dos subprogramas do Pronaf, $58 \%$ respondeu negativamente. Os motivos apontados para o não acesso foram: elevada burocracia; juro alto; falta de informações sobre a linha e as condições de acesso; não ter Declaração de Aptidão ao Pronaf (DAP); pouco tempo desde o início da unidade de produção ${ }^{9}$; receio quanto ao endividamento; não ter interesse. O restante dos entrevistados, ou seja, $42 \%$ afirmou acessar os

6 Laranjal e Palmital são municípios que não pertencem ao Território da Cidadania da Cantuquiriguaçu, apesar disto as entrevistas com os agricultores foram mantidas por estarem comercializando no Território.

7 Esta área foi mencionada pelos acampados, considerando que se trata do tamanho programado dos lotes, a serem divididos entre os acampados quando ocorrer o assentamento.

8 Cabe destacar que na FESA predominam expositores que atuam de modo cooperativo ou associativo, pelas características da feira. A rede mencionada pelos agricultores é a Ecovida, constituída pela união de associações, cooperativas, Agroindústrias, comércio e atores envolvidos com a Agroecologia. Esta forma núcleos em cada região para proporcionar momento para seus envolvidos com troca de informações, experiências, produtos além de possibilitar a certificação participativa. Dessa forma essa rede incentiva a produção e comercialização de produtos orgânica e Agroecologia

${ }^{9}$ Estas são respostas comuns aos acampados. 
subprogramas Pronaf Custeio e Mais Alimentos. Nestes casos o destino mencionado, para a utilização dos recursos, é investimento, financiamento de máquinas, equipamentos, infraestrutura, animais e sementes para atividades agropecuárias (como bovinocultura, produção de milho e seda).

Sobre o acesso ao subprograma Pronaf Agroecologia observou-se que este não aconteceu, conforme as informações apresentadas na seção 2. Apenas dois agricultores, dentre os entrevistados, afirmaram que sabiam da existência do subprograma, sendo que um deles afirmou ter tentado o acesso durante 4 anos em uma instituição financeira. Esse agricultor mencionou que o agente financeiro que ele procurava alegava não ter informações sobre esta linha, até que procurou outra instituição financeira, na qual conseguiu acessar o recurso desejado em linha distinta, na do Pronaf Custeio. O segundo agricultor que manifestou saber da existência do Pronaf Agroecologia, por estar acampado não tinha DAP (que é um dos requisitos do Pronaf) e mencionou que quando for assentado tem interesse em acessar o recurso do subprograma.

Ao realizar a entrevista a maioria dos entrevistados indicava desconhecimento sobre a linha de crédito do Pronaf Agroecologia. A partir dessa verificação, e com a hipótese de que novas entrevistas com agricultores resultariam em respostas semelhantes, a decisão das pesquisadoras foi procurar as instituições financeiras que trabalham com o Pronaf ${ }^{10}$, em especial com o subprograma Pronaf Agroecologia. Com esses agentes financeiros o objetivo foi conhecer os motivos pelos quais os agricultores familiares da região não acessam a linha mencionada, buscando ainda comparar e confrontar as respostas obtidas nos dois grupos.

Neste ínterim foram contatadas cinco (5) instituições financeiras com atuação na região de abrangência da pesquisa. Dessas, foi possível realizar a pesquisa em quatro (4), tendo sido entrevistados agentes financeiros que atuam diretamente com as linhas de crédito do Pronaf. As instituições pesquisadas foram denominadas com as letras A, B, C e D preservando o sigilo das informações e dos informantes. Nas informações obtidas procurou-se complementar a compreensão quanto aos limites e potencialidades do acesso à linha do Pronaf Agroecologia no Território da Cidadania Cantuquiriguaçu.

No caso da instituição financeira A observou-se que não houve demanda pela linha do Pronaf Agroecologia nos últimos anos ${ }^{11}$. Para o agente financeiro entrevistado nesta instituição, as principais dificuldades que os agricultores têm para acessar à linha destinada à agroecologia no Pronaf estão na apresentação da documentação exigida para poder acessar o recurso. Constatou-se que nessa instituição são frequentes os casos de agricultores que não conseguem atender as

\footnotetext{
${ }^{10}$ Esta hipótese foi se fortalecendo na medida em que foram sendo realizadas as entrevistas com os agricultores familiares, pois a alegação de desconhecimento sobre a existência da linha do Pronaf Agroecologia era frequente. Inclusive durante as entrevistas na FESA uma das agricultoras cobrou um funcionário de instituição financeira que estava próximo, questionando os motivos pelos quais este nunca lhe havia informado sobre a existência da linha em questão.

${ }^{11}$ Nesta instituição são frequentes os acessos às linhas do Pronaf Custeio (manutenção) e Mais Alimentos (investimento). O agente entrevistado mencionou que em 2018, após a realização da FESA, alguns agricultores familiares procuraram informações sobre a linha do Pronaf Agroecologia. Ainda que não se tenha certeza, acredita-se que estes questionamentos tenham sido estimulados pela pesquisa aplicada pelas autoras durante o evento.
} 
exigências tais como a apresentação da DAP, e a inexistência de bens patrimoniais compatíveis para a geração de limite de crédito considerando a tentativa de acesso às linhas mais convencionais, tais como Custeio e Mais Alimentos. No entendimento do agente entrevistado, o principal motivo para a falta de acesso são as restrições impostas pela linha, as dificuldades dos agricultores em conhecer melhor o subprograma e ainda a falta de ações de divulgação do banco direcionadas para os agricultores familiares em relação ao Pronaf Agroecologia ${ }^{12}$.

$\mathrm{Na}$ instituição financeira $\mathrm{B}$ o agente entrevistado afirmou que não há divulgação da linha do Pronaf Agroecologia, que os agricultores desconhecem as informações sobre este subprograma e suas condições de acesso, bem como ignoram as vantagens proporcionadas pela linha, o que acaba por evitar que procurem informações. Em relação às dificuldades para os agricultores familiares acessarem o Pronaf em todas as linhas e na agroecologia o agente apontou para: 0 não enquadramento do agricultor no subprograma; as burocracias exigidas em termos de documentações; desinteresse por parte das instituições financeiras em atender aos agricultores familiares por serem operações com menores valores. Este agente admitiu que o Pronaf é um programa que propicia menor rentabilidade para as instituições, por isso não faz parte do foco e das metas prioritárias das agências dessa instituição, isso acaba por constituir mais um obstáculo ao agricultor para o acesso ao programa.

Assim, a partir da pesquisa na instituição $B$, as dificuldades de expansão da linha do Pronaf Agroecologia estão relacionadas, principalmente, à falta de informações disponíveis para os agricultores e a falta de incentivo por parte das instituições financeiras para disponibilizar o crédito. $O$ agente alegou que as instituições com viés social tendem a se preocupar com o agricultor ou com o desenvolvimento sustentável (atuando na linha do Pronaf Agroecologia), porém nos bancos convencionais a preocupação central é com a rentabilidade. $E$ nestes casos, como o subprograma Pronaf Agroecologia tende a disponibilizar montantes reduzidos para acesso, não está no foco prioritário destas instituições. Entretanto, as respostas indicaram que se a demanda fosse suficientemente atraente o banco dedicaria atenção para este subprograma, entretanto esta não é a realidade atual.

Do ponto de vista do agente entrevistado no Banco $B$, as instituições de assistência técnica, que atendem agricultores familiares, deveriam auxiliar para que fosse possível ao público alvo apresentar os projetos com viabilidade justificada. Mencionou que a instituição financeira não tem condições de ir nas propriedades prospectar demandas e orientar os agricultores, que esta é uma tarefa da assistência técnica. Deste modo, segundo o entrevistado há desconhecimento sobre o subprograma Pronaf Agroecologia por parte dos agricultores e da assistência técnica, além do desinteresse por parte dos agentes financeiros em disponibilizar a linha, pelos motivos já elencados anteriormente.

$\mathrm{Na}$ instituição $\mathrm{C}$ o agente financeiro entrevistado mencionou que a maior parte dos agricultores não sabe o que é a agroecologia e a conservação ambiental,

\footnotetext{
${ }^{12}$ Cabe destacar que durante a entrevista nesta instituição foi possível observar que o entrevistado mencionou ter sido necessário buscar maiores informações sobre o subprograma Pronaf Agroecologia, para esclarecer aos agricultores que lhes procuraram após a FESA 2018.
} 
por isso não tem consciência de como fazer melhor. A instituição além da linha do Pronaf Agroecologia também oferta o Pronaf Eco, mas segundo o entrevistado não há demanda para tais linhas. Em sua opinião, os fatores que dificultam o acesso dos agricultores familiares ao subprograma Pronaf Agroecologia são: desconhecimento da linha de crédito, burocracia da operação desde a obtenção da carta de aptidão até o acesso ao crédito (o que envolve desde a obtenção de licenças e a documentação em geral).

$\mathrm{Na}$ instituição $\mathrm{D}$ o agente financeiro, entrevistado, também mencionou não haver demanda pela linha do Pronaf Agroecologia. Em sua compreensão a agroecologia consiste em um meio de produção e vida que prevê uma sintonia com a natureza, produção e consumo de alimentos saudáveis, mas continuamos inseridos em uma sociedade que segue a lógica do mercado, no qual a busca ainda é pelos resultados financeiros. Dessa forma há um processo de convencimento de que o meio de produção mais adequado é o convencional, por isso predomina a ideia de que se deva seguir as regras do mercado e consumir insumos do "pacote tecnológico".

Assim como nas outras instituições financeiras pesquisadas, na D não há demanda pelo subprograma em questão. O agente financeiro destaca que no início das atividades desta instituição financiavam a produção agroecológica (de mel, cebola, hortaliças), o que acabou sendo alterado por pressões do mercado. Para manter os resultados financeiros, segundo o agente, a instituição teve de abrir mão destas linhas e focar no financiamento do modelo convencional, mencionando inclusive que se não aderissem ao financiamento de soja transgênica não sobreviveriam no mercado financeiro.

Quanto às dificuldades de acesso à linha do Pronaf Agroecologia, relatadas pelo agente da Instituição D, estas são: a) dificuldades de o agricultor dispor da documentação exigida para o financiamento; b) condições de enquadramento na linha de crédito; c) inexistência de restrição para a obtenção do crédito. Assim, questões burocráticas e de restrições em termos de capital acabam por barrar o acesso ao subprograma em questão.

Deste modo, a partir das entrevistas realizadas com os agricultores familiares e os agentes das instituições financeiras, ficou evidente a falta de conhecimentos e de condições de atender à burocracia necessária por parte dos agricultores familiares. $O$ fato de haver uma série de exigências documentais e financeiras para o acesso à linha é entrave para que o agricultor seja estimulado a buscar mais informações. Enquanto há falta de divulgação de informações sobre a linha do Pronaf direcionada para a agroecologia por parte das instituições financeiras. Ainda é possível constatar que estas focam preferencialmente nas linhas que thes permitem obter maiores retornos ${ }^{13}$.

No caso das instituições financeiras há ainda outra constatação, a de que nem as instituições financeiras nem o governo vem agindo para estimular o acesso aos recursos disponibilizados para a agroecologia. E na relação entre os agricultores e as instituições financeiras é perceptível a ausência da assistência técnica que

\footnotetext{
${ }^{13}$ Cabe destacar que os agentes financeiros demonstraram compreender claramente o que significa a agroecologia e em geral manifestaram preocupação pelo fato de as instituições não estarem ofertando recursos pelo subprograma.
} 
poderia ser um ator fundamental para ampliar as informações disponíveis para o agricultor, podendo orientar quanto ao acesso e uso de recursos da linha, bem como em viabilizar melhores condições para o acesso. Assim, seja no âmbito federal, estadual ou municipal o fortalecimento da assistência técnica parece ser uma alternativa importante para estimular a agroecologia e ampliar as possibilidades de acesso aos recursos disponíveis.

\section{Considerações finais}

Esse trabalho de pesquisa fez uma análise das condições de acesso para a produção agroecológica, junto ao Programa Nacional de Fortalecimento da Agricultura Familiar, no Território da Cidadania Cantuquiriguaçu, no Estado do Paraná.

Os dados primários para a compreensão dos dados secundários disponíveis, foram coletados em uma pesquisa que buscou entrevistar agricultores familiares e posteriormente agentes financeiros que trabalham com o Pronaf. Com isso foi possível fazer uma análise dos limites e potencialidades do Programa Nacional de Fortalecimento da Agricultura Familiar, no Território da Cidadania Cantuquiriguaçu, destacando o acesso para a agroecologia.

Nas pesquisas efetuadas com os agricultores familiares constatou-se que, em sua maioria, os entrevistados desconheciam o subprograma do Pronaf voltado para a Agroecologia. Além deste desconhecimento, apontaram motivos para não acessar ao Pronaf: a elevada burocracia, as condições de acesso, a falta de informações sobre a linha, a não disponibilidade de documentos como a DAP, o receio em relação ao endividamento. Com base nas respostas obtidas junto aos agricultores familiares, a pesquisa foi direcionada para as instituições financeiras, nas quais as entrevistas buscaram complementar as informações obtidas com os agricultores familiares.

Constatou-se nas entrevistas junto às instituições financeiras, um alinhamento das respostas àquelas informações que os agricultores entrevistados haviam mencionado. Nos dois grupos observou-se que apresentavam pouco conhecimento em relação ao subprograma. No caso das instituições financeiras os agentes apontaram elementos explicativos sobre os motivos pelos quais não ofertam a linha. Observou-se que os entrevistados demonstravam preocupação pelo desconhecimento, tentando justificar os motivos pelos quais as instituições não estavam ofertando a linha.

$\mathrm{Na}$ maior parte das instituições financeiras pesquisadas, foi dito que se houver demanda pela linha, haverá mobilização para ofertá-la. Entretanto, após as pesquisas cabe questionar: Como haverá demanda se os agricultores não sabem da existência dessa linha e desconhecem procedimentos para acessá-la? A divulgação e orientação são de extrema importância para o sucesso da linha. Isso é observado em uma entrevista com a instituição financeira $B$, na qual foi mencionado que após a FESA houve procura por parte de agricultores para entender a linha. É curiosa esta situação pelo fato de que essa foi uma das feiras nas quais a pesquisadora realizou entrevistas, acreditando que a demanda tenha surgido a partir destes questionamentos. 
Na maior parte dos agentes financeiros pesquisados foi destacado o papel da assistência técnica na divulgação da linha, pois é essa que auxilia o agricultor no momento de elaboração do projeto para acessar os recursos do Pronaf. Algumas das instituições ainda mencionaram que o governo deveria atuar efetivamente no estímulo para a divulgação da linha. Contrapondo as respostas percebe-se que os agricultores familiares indicam que as instituições financeiras não informam sobre a linha, já as instituições financeiras atribuem a falta de divulgação a uma carência de atuação da assistência técnica e dos próprios governos (nas três esferas). Neste sentido há falta de um sistema que funcione com o cumprimento efetivo do papel de cada uma das partes.

As políticas públicas são parte importante da composição do sistema econômico de um país, e no caso deste trabalho para os agricultores familiares. Assim, para que funcionem é preciso que sejam incentivadas pela assistência técnica, agentes financeiros e públicos (municipais, estaduais e federais) para a efetiva utilização por parte dos agricultores familiares. E que deste modo consiga contribuir com sua função no desenvolvimento da região e não apenas permanecer no papel, como é o caso dos recursos disponíveis para o subprograma Pronaf Agroecologia.

Deste modo, pode-se afirmar que os limites observados nessa pesquisa quanto ao acesso dos agricultores familiares à linha do Pronaf voltada para a agroecologia são: desconhecimento por parte dos possíveis beneficiários quanto aos procedimentos para acesso, dificuldades para atendimento às exigências de acesso à linha (principalmente em relação aos documentos), receio do endividamento, falta de divulgação e de interesse por parte das instituições na linha. As potencialidades ou oportunidades, por sua vez, são viabilizar a produção orgânica ou agroecológica, garantir segurança alimentar, preservação do meio ambiente, e atendimento a um mercado diferenciado, por meio da utilização de recursos disponibilizados para a linha, mas não acessados pelos agricultores familiares.

Em uma perspectiva otimista, imaginando um cenário em que todos tenham interesse que os recursos existentes para a produção agroecológica sejam realmente acessados, acredita-se que isso possa acontecer quando o agricultor familiar começar a ter conhecimentos necessários para realizar a transição agroecológica apoiado por assistência técnica, seja na elaboração do projeto e outras orientações. Avançar na produção agroecológica é uma potencialidade a ser explorada, pois, conforme já destacado no início deste artigo, contribui na segurança alimentar e nutricional, na agro biodiversidade, no uso sustentável dos recursos provenientes da natureza, ampliando a autonomia do agricultor, contribuindo na geração de trabalho e renda e impulsionando a economia local.

Após a finalização desse trabalho constatou-se que são necessários novos estudos, tais como pesquisas referentes à atuação da assistência técnica no que tange ao estímulo para que os agricultores familiares consigam acessar aos recursos destinados para a agroecologia. A experiência do Estado da Paraíba parece dar algumas indicações de como é possível ampliar o acesso para os agricultores familiares, sendo que naquele caso, ao menos em termos teóricos o que se sabe é que há diversas instituições atuando em prol da disponibilidade de acesso aos recursos voltados para a agroecologia dentro do Pronaf. 


\section{REFERÊNCIAS}

ABRAMOVAY, Ricardo. Agricultura familiar e desenvolvimento territorial: Reforma agrária, 1998. Disponível em: http://wp.ufpel.edu.br/ppgdtsa/files/2014/10/TextoAbramovay-R.-Agricultura-familiar-e-desenvolvimento-territorial.pdf Acesso em: 12 set. 2017.

ALMEIDA, Jalcione (org.). A modernização da agricultura. Coordenado pela Universidade Aberta do Brasil - UAB/UFRGS e pelo Curso de Graduação Tecnológica - Planejamento e Gestão para o Desenvolvimento Rural da SEAD/UFRGS. - Porto Alegre: Editora da UFRGS, 2011.

ALTIERI, Miguel. Agroecologia: a dinâmica produtiva da agricultura sustentável. 4 ed. Porto Alegre: Editora da UFRGS, 2004.

ALTIERI, Miguel A. Agroecologia: bases científicas para uma agricultura sustentável. 3.ed, São Paulo: Expressão Popular, 2012.

BACEN. Matriz de Dados do Crédito Rural - MDCR. Disponível em:

https://www.bcb.gov.br/estabilidadefinanceira/micrrural Acesso em: 16 dez. 2018.

BIANCHINI, Valter. Vinte Anos do PRONAF, 1995-2015. Avanços e Desafios. Brasília: SAF/MDA, 2015. Disponível em:

http://atividaderural.com.br/artigos/568ba26e514e2.pdf Acesso em 11 abr. 2018.

BOMBARDI, Larissa Mies. Agrotóxicos e agronegócio: arcaico e moderno se fundem no campo brasileiro. 2012. Disponível em:

http://www.reformaagrariaemdados.org.br/sites/default/files/Agrot\%C3\%B3xicos\%20 e\%20agroneg\%C3\%B3cio\%20-

\%20arcaico\%20e\%20moderno\%20se\%20fundem \%20no\%20campo\%20brasileiro\%20(Lari ssa\%20M.\%20Bombardi).pdf Acesso em: 2 out. 2018.

BRASIL. Mais 74 Territórios Rurais são incluídos em programa de desenvolvimento. Disponível em: http://www.brasil.gov.br/governo/2013/05/mais-74-territorios-ruraissao-incluidos-em-programa-de-desenvolvimento Acesso em: 19 de nov. de 2018.

BRASIL. Planalto. Decreto 9.064, de 31 de maio de 2017. Disponível em: http://www.planalto.gov.br/ccivil_03/_Ato2015-2018/2017/Decreto/D9064.htm Acesso em: 16 jan. 2019.

BUAINAIN, Antônio Márcio. Agricultura familiar, Agroecologia e Desenvolvimento Sustentável: questões para debate. IICA. 2006. Disponível em: http://www.iicabr.iica.org.br/wp-content/uploads/2014/03/Serie-DRS-vol-5Agricultura-familiar-agroecologica-e-desenvol-sustentavel.pdf Acesso em: 01 jun. 2018. 
CHIZZOTTI, Antônio. Pesquisa qualitativa em ciências humanas e sociais.

Petrópolis/RJ: Editora Vozes, 2006.

CONDETEC. Território Cantuquiriguaçu Paraná Diagnostico Socioeconômico. 2004. Disponível em: <http://www.iapar.br/arquivos/File/zip_pdf/cantuquiriguacu.pdf>. Acesso em: 19 de nov. de 2018.

CONDETEC. Território Cantuquiriguaçu Paraná Plano Safra Territorial 2010 - 2013. 2011. Disponível em: <http://www.cantuquiriguacu.com.br/pdf/pst_condetec.pdf>. Acesso em: 19 de nov. de 2018.

DELGADO, Guilherme Costa. A Questão Agrária E O Agronegócio No Brasil. Combatendo A Desigualdade Social O Mst E A Reforma Agrária No Brasil. Editora Unesp. 2008. Disponível em: https://edisciplinas.usp.br/pluginfile.php/ $233593 / \mathrm{mod}$ resource/content $/ 1 /$ Carter $\% 20$ Combatendo $\% 20 a \% 20$ desigualdade $\% 20$ so cial.pdf Acesso em: 5 dez. 2018.

DELGADO, Guilherme Costa. Do capital financeiro na agricultura à economia do Agronegócio. Porto Alegre/RS: Editora da UFRGS, 2012.

FUNAI. Índios no Brasil. Disponível em: http://www.funai.gov.br/index.php/indiosno-brasil/terras-indigenas Acesso em: 20 nov. 2016.

GAZOLLA, Marcio; SCHNEIDER, Sergio. As Duas "Caras" do Pronaf: Produtivismo ou fortalecimento da produção para autoconsumo? 2004. Disponível em:

http://www.reformaagrariaemdados.org.br/sites/default/files/As\%20duas\%20caras\%2 odo\%20PRONAF, $\% 2$ pprodutivismo\%200u\%20fortalecimento\%20da $\% 20$ producao $\% 20$ pa ra\%200\%20autoconsumo\%20-\%20Marcio\%20 Gazolla,\%20Sergio\%20Schneider.pdf.

Acesso em: 8 dez. de 2018.

GIL, Antônio Carlos. Métodos e técnicas de pesquisa social. 6. ed. São Paulo: Editora Atlas, 2008.

GOVERNO DA PARAÍBA. Notícias. Disponível em: <http://paraiba.pb.gov.br/>. Acesso em 19 de nov. de 2018.

GOVERNO DO PARANÁ. Fundo de aval garantidor da agricultura familiar - FAR. Disponível em:

http://www.fomento.pr.gov.br/modules/conteudo/conteudo.php?conteudo=32 Acesso em: 5 nov. 2018.

HEBERLÊ, Antônio Luiz Oliveira et al. Agricultura familiar e pesquisa agropecuária: contribuições para uma agenda de futuro100. In: DELGADO, Guilherme Costa. BERGAMASCO, Sonia Maria Pessoa Pereira (orgs.) Agricultura Familiar Brasileira: Desafios e Perspectivas de Futuro. Brasília: Ministério do Desenvolvimento 
Agrário, 2017. Disponível em: https://www.cfn.org.br/wpcontent/uploads/2017/10/Agricultura_Familiar.pdf Acesso em: 15 abr. 2018.

IBGE. IBGE-Cidades. Disponível em: http://cidades.ibge.gov.br/xtras/perfil.php? codmun=412090 Acesso em: 15 nov. 2016.

IBGE. Censo Agropecuário 2006 Agricultura Familiar Primeiros Resultados. 2009. Disponível em: https://biblioteca.ibge.gov.br/visualizacao/periodicos/50 lagro_2006_agricultura_familiar.pdf Acesso em: 5 jul. 2018.

IBGE. Censo Agropecuário 2006 - Segunda Apuração. Disponível em: https://sidra.ibge.gov.br/pesquisa/censo-agropecuario/censo-agropecuario2006/segunda-apuracao Acesso em: 8 jul. 2018. A.

IBGE. Censo Agropecuário 2017 - Resultados Preliminares. Disponível em: https://sidra.ibge.gov.br/pesquisa/censo-agropecuario/censo-agropecuario-2017 Acesso em: 8 jul. 2018. B.

ITCG. Terras e Territórios quilombolas, indígenas e da reforma agrária no Estado do Paraná. 2008. Disponível em: http://www.itcg.pr.gov.br/arquivos/File/ Produtos_DGEO/Mapas_ITCG/PDF/Mapa_social_A1_2008.pdf Acesso em: 19 nov. 2018.

LEI 11326/06 de 24 de julho de 2006. Estabelece as diretrizes para a formulação da Política Nacional da Agricultura Familiar e Empreendimentos Familiares Rurais. Presidência da República, Casa Civil: subchefia para assuntos jurídicos, 2010. Disponível em: http://www.planalto.gov.br/ccivil_03/_Ato20042006/2006/Lei/L11326.htm Acesso em: 10 mai. 2018.

LUCENA, Romina Batista de. O papel da agricultura no desenvolvimento econômico brasileiro, 1980/1998. 2000. 156 f. Dissertação (Mestrado em Economia) - Universidade Federal do Rio Grande do Sul, Curso de pós-graduação em Economia, Porto Alegre, 2000. Disponível: www.lume.ufrgs.br/bitstream/handle/ 10183/2547/000276725.pdf;sequence=1 Acesso em: 15 abr. 2018.

MANFIOLLI, Marcelo Hussar. Os Efeitos do PAA e do PNAE na Agricultura Familiar da Região Administrativa de Paranavaí. 2014. 79 f. Dissertação (Mestrado em Políticas Públicas) - Universidade Estadual de Maringá, Programa de pós-graduação em Políticas Públicas, Maringá, 2014. Disponível em:

http://www.escoladegestao.pr.gov.br/arquivos/File/1_Producoes_Academicas/ Os_Efeitos_do_PAA_e_do_PNAE_na_Agricultura_Familiar_da_Regiao_Administrati va_de_Paranavai_Marcelo_Hussar_Manfiolli.pdf Acesso em: 15 abr. 2018.

MARCONI, Marina de Andrade; LAKATOS, Eva Maria. Fundamentos de metodologia científica. $7^{\text {a }}$ edição. São Paulo: Atlas, 2010. 
MCR. Manual do Crédito Rural. Atualização MCR n 649, de 13 de junho de 2018. Disponível em: https://www3.bcb.gov.br/mcr Acesso em: 10 jun. 2018.

MDA. Brasil Agroecologia Plano nacional de Agroecologia e produção orgânica PLANAPO. 2013. Disponível em: http://www.mda.gov.br/sitemda/ sites/sitemda/files/user_img_19/BrasilAgroecologico_Baixar.pdf Acesso em: 12 abr. 2018.

MDA. Brasil Agroecológico Plano Nacional de Agroecologia e Produção Orgânica Planapo 2016-2019. 2016. Disponível em:

http://www.mda.gov.br/sitemda/sites/sitemda/files/ceazinepdf/PLANAPO_2016_201 9.pdf Acesso em: 5 ago. 2018. A

MDA. Plano Safra da agricultura familiar 2016-2017. 2016. Disponível em: http://www.mda.gov.br/sitemda/sites/sitemda/files/ceazinepdf/cartilha_plano_safra 2016_2017_1.pdf Acesso em: 19 nov. 2018. B.

MDA. Relatório de balanço 2013 - 2015. 2016. Disponível em: http://www.mda.gov.br/sitemda/sites/sitemda/files/user_arquivos_3/relatorio_de_b alanco_2013_2015.pdf Acesso em: 12 de abr. de 2018. C.

MDA, CADERNO PRONAF AGROECOLOGIA. Disponível em: http://www.mda.gov.br/sitemda/sites/sitemda/files/ceazinepdf/CADERNO_PRONAF _AGROECOLOGIA_FINAL.pdf Acesso em: 29 de jun. de 2018. D

OLIVEIRA, Maria Marly de. Como fazer pesquisa qualitativa. Petrópolis/RJ: Editora Vozes, 2007.

PLOEG, Jan Douwe Van Der. Camponeses e Impérios Alimentares lutas por autonomia e sustentabilidade na era da globalização. Porto Alegre/RS: Editora UFRGS. 2008.

PORTAL DOS NEDETS. Caderno de Informações Territoriais. Brasília: 2016. Disponível em: http://portaldosnedets.info/site/ Acesso em 10 mai. 2018

SARANDÓN, Santiago Javier; FLORES, Claudia Cecilia. Agroecología: bases teóricas para el diseño y manejo de Agroecosistemas sustentables. Editorial de la Universidad de La Plata. Buenos Aires, Argentina. 2014.

TOSETTO, Eleonora Escobar. Identificação das causas das subnotificações das intoxicações da população exposta a agrotóxicos: estudo de caso de Laranjeiras do Sul-PR. 125f. Dissertação (Mestrado) - Universidade Federal da Fronteira Sul, Programa de Pós-Graduação em Agroecologia e Desenvolvimento Rural Sustentável. 2016. Disponível em: https://rd.uffs.edu.br/bitstream /prefix/605/1/TOSETTO.pdf Acesso em: 2 de out. de 2018. 
VEIGA, José Eli Da. Agricultura familiar e sustentabilidade. Cadernos de Ciência \& Tecnologia, v. 13, n. 3, p. 383-404. Brasília. 1996. Disponível:

https://seer.sct.embrapa.br/index.php/cct/article/view/9009/5115 Acesso em: 1 de jul. de 2018.

YIN, Robert K. Pesquisa Estudo de Caso-Desenho e Métodos. Porto Alegre: Edições Bookman, 1994.

Janete Stoffel. Doutora em Desenvolvimento Regional. Universidade Federal da Fronteira Sul. Docente. Rodovia BR 158 - Km 405, CEP 85301-970. Laranjeiras do Sul/RS. janete.stoffel@gmail.com

Anelise Graciele Rambo. Doutora em Desenvolvimento Rural. Universidade Federal do Rio Grande do Sul - Campus Litoral Norte. Docente. Km 92, RS-030, 11.700, Tramandaí-RS, CEP 95590-000. anelise.rambo@ufrgs.br

Patrícia Luiza Eberhardt. Graduada em Ciências Econômicas. Universidade Federal da Fronteira Sul. Linha Alto São João, s/n, Zona Rural de Laranjeiras do Sul, CEP. 85319-899. patricialuizaeberhardt@gmail.com

Como citar: STOFFEL, Janete; RAMBO, Anelise Graciele; EBERHARDT, Patrícia Luiza. Condições de acesso à linha do Pronaf Agroecologia no Território da Cantuquiriguaçu/PR. Redes (St. Cruz Sul, Online), Santa Cruz do Sul, v. 25, n. 2, p. 809-831, mar. 2020. ISSN 19826745. Disponível em: https://online.unisc.br/seer/index.php/redes/article/view/13602 Acesso em: 15 maio 2020. doi: https://doi.org/10.17058/redes.v25i2.13602

\section{CONTRIBUIÇÃO DE CADA AUTOR}

a. Fundamentação teórico-conceitual e problematização: Janete Stoffel, Anelise Graciele Rambo, Patrícia Luiza Eberhardt

b. Pesquisa de dados e análise estatística: Janete Stoffel, Anelise Graciele Rambo, Patrícia Luiza Eberhardt

c. Elaboração de figuras e tabelas: Janete Stoffel, Anelise Graciele Rambo, Patrícia Luiza Eberhardt

d. Fotos: não se aplica

e. Elaboração e redação do texto: Janete Stoffel, Anelise Graciele Rambo, Patrícia Luiza Eberhardt

f. Seleção das referências bibliográficas: Janete Stoffel, Anelise Graciele Rambo, Patrícia Luiza Eberhardt

Fontes de financiamento: não se aplica 